\title{
Predictors of intentions to use cigarettes and electronic-cigarettes among high school students
}

This article was published in the following Dove Press journal:

Journal of Multidisciplinary Healthcare

\author{
Josefina Patiño-Masó' \\ Sílvia Font-Mayolas ${ }^{2}$ \\ Anna Salamó ${ }^{2}$ \\ Montserrat Arboix ${ }^{3}$ \\ Mark JM Sullman ${ }^{4}$ \\ Maria-Eugenia Gras ${ }^{2}$ \\ 'Department of Nursing, Institut de \\ Recerca Sobre Qualitat de Vida, \\ Universitat de Girona, Girona, Catalunya, \\ Spain; ${ }^{2}$ Department of Psychology, \\ Institut de Recerca Sobre Qualitat de \\ Vida, Universitat de Girona, Girona, \\ Catalunya, Spain; ${ }^{3}$ Department of Health, \\ Escola Municipal del Treball, Granollers, \\ Catalunya, Spain; ${ }^{4}$ Department of Social \\ Sciences, School of Humanities and Social \\ Sciences, University of Nicosia, Nicosia, \\ Cyprus
}

\begin{abstract}
Purpose: Tobacco is the second most commonly used drug by Spanish high school students and e-cigarette use has increased over the last three years among this population. Students who reported smoking tobacco and/or e-cigarette use often have friends and family that also consume these substances. The aims of the present study were to: determine the prevalence of tobacco and electronic cigarette consumption among young adolescents, the age of initiation and the intention to consume both of these substances in the future; study the relationships between their current tobacco and e-cigarette consumption status, intentions to consume these substances in the future and the consumption of these substances by family members living in their home and friend's consumption status; investigate the relationship between their current tobacco and e-cigarette consumption status, friends' consumption status and their intention to consume each substance in the future; analyse the relationship between current consumption status, intentions to consume in the future and perceived risk; identify the main predictors of intentions to use these substances in the future.
\end{abstract}

Methods: A cross-sectional survey was conducted in 2017. The sample consisted of 468 school students in the first cycle of secondary education in Catalonia, Spain. The participants who were aged between 11 and 15 years old, with $49.4 \%$ being female.

Results: A stepwise binary logistic regression showed that the best predictors of the intention to smoke tobacco in the future were: having tried tobacco, being a current consumer, having a family member smoking at home and having a low perceived risk of smoking. The best predictors of the intention to use electronic cigarettes in the future were: having tried tobacco, being a current consumer and having friends who smoke or use electronic cigarettes.

Conclusion: Smoking prevention programs must consider the social network surrounding teenagers, particularly close friends and family. Intervention strategies for delaying the onset of tobacco or e-cigarette consumption are greatly needed.

Keywords: adolescence, tobacco use, electronic cigarette, parental smoking, risk perceptions, adolescent smoking

\section{Introduction}

A national survey in 2016 found that tobacco was the second most prevalent drug among Spanish high school students aged between 14 and 18 years old. Over one third (38.5\%) reported having smoked tobacco during their lifetime, $27.3 \%$ in the last 30 days and $8.8 \%$ of the participants reported daily use. Nearly half $(47.8 \%)$ reported living with a daily smoker at home and $91.8 \%$ believed that smoking a pack of cigarettes every day could cause health problems. Among those students who reported smoking, $60.4 \%$ said their parents allowed it. Furthermore, $64.9 \%$ of students who reported smoking tobacco said that all or nearly all of their friends
Correspondence: Josefina Patiño-Masó Universitat de Girona, Facultat d'Infermeria, Emili Grahit 77, Campus Centre, Girona 17003, Spain

Tel +349724I 8770

Fax +34972418773

Email josefina.patino@udg.edu 
also smoked compared to $35.1 \%$ among non-smokers. ${ }^{1}$ However, in another study of 526 Spanish adolescents, aged between 12 and 15 years old, no relationship was found between tobacco use and having friends who smoked. $^{2}$

According to the 2016 national survey, the prevalence of lifetime electronic cigarette use (e-cigarettes) among Spanish high school students (aged between 14 and 18 years old) increased from $17 \%$ in 2014 to $20.1 \%$ in 2016. Among students who reported having used e-cigarettes, the most frequent users were men $(56.9 \%)$ who had also smoked tobacco at some point in their life (78.7\%) and whose parents allowed e-cigarette use (26\%). Among those students who reported having used e-cigarette, $88 \%$ believed that smoking a pack of cigarettes every day could cause health problems, compared to $92.8 \%$ who had not used e-cigarettes. ${ }^{1}$

In 2017, the perceived risk of e-cigarettes and cigarettes among 3,311 adolescents (aged between 13 and 18 years old) attending two schools in the Castilla \& Leon region of Spain found that $74.3 \%$ and $65.9 \%$ considered the occasional consumption of tobacco and e-cigarettes to be "very dangerous", respectively. ${ }^{3}$ This finding is particularly important, since e-cigarette use is considered a gateway to the initiation of conventional tobacco smoking. ${ }^{4-6}$

Previous research has also investigated the reasons for using e-cigarettes. In a 2016 study of 4,049 US middle and high school students, the most common reasons for using e-cigarettes were reported to be: that they were used by a friend or family member (39\%), the availability of flavours such as mint, candy, fruit or chocolate (31\%), and the belief that e-cigarettes are less harmful than smoking tobacco $(17.1 \%){ }^{7}$ In another study of 14,151 US high school students researchers found that those who had used e-cigarettes in the last 30 days also reported conventional smoking to be less addictive than non-users reported. ${ }^{8}$ Furthermore, a study of 2,664 US high school students, who had reported using e-cigarette at some point in their life, three different types of e-cigarette users were identified, adolescents who vaped: to experiment (29.4\%), to replace-cigarettes $(7.3 \%)$, and for taste plus entertainment (63.4\%). ${ }^{9}$ In the UK, focus group using a sample of 83 (aged 14-17 years old) current e-cigarette users found that there was a lack of information regarding the precise ingredients and risks, a view that e-cigarettes were substantially less harmful than conventional smoking, and the perception that e-cigarettes were attractive, fun and had great flavours. ${ }^{10}$ Moreover, Pepper et al. ${ }^{11}$ surveyed 1,589 US adolescents (aged 15-17) who reported e-cigarette use in the past 30 -days and found that only $34 \%$ of the participants knew that nicotine was derived from tobacco.

Although several studies have investigated smoking and e-cigarette use among adolescents aged 13-18 years old, very little information exists for teenagers under 13 years old. This is despite the fact that the peak years for first trying tobacco products is between the ages of 11 and 13 years old. ${ }^{12}$ During these early teenage years, the smoking and e-cigarette use of these young adolescents are strongly influenced by the corresponding behaviour of their parents and peers. ${ }^{13}$

It is important to note that the earlier a person starts to use tobacco products, the greater the risk of smoking-related health problems in adulthood. ${ }^{14}$ This study attempts to fill the gaps in the research literature in relation to the first experience of smoking and e-cigarette use among young teenagers and the influence of their social network (parents and peers) on the initiation, intention to consume and maintenance of consumption of these substances.

The main hypothesis of this research were the following. The age at which students start smoking cigarettes and using e-cigarettes is younger than 14 years old. The main predictors of using these substances in the future, for students under 15 years old, are: having tried cigarettes or e-cigarettes, the current use of cigarettes or e-cigarettes, having family members or friends that smoke tobacco or use e-cigarettes and a low perceived risk of smoking cigarettes or using e-cigarettes.

The aims of the present study were fivefold. Firstly, to determine the prevalence of tobacco and electronic cigarette consumption among young adolescents, the age of initiation and the intention to consume both of these substances in the future. Secondly, to study the relationship between their current tobacco and e-cigarette consumption, intentions to consume these substances in the future and the consumption of family members in their home. Thirdly, to investigate the relationship between their current tobacco and e-cigarette consumption status, friends' consumption status and intentions to consume each substance in the future. The fourth aim was to investigate the relationship between current consumption status, intentions to consume in the future and perceived risk. Finally, the study also set out to identify the main predictors of intentions to use these substances in the future.

\section{Methods}

\section{Participants and procedure}

A cross-sectional descriptive study was conducted from April to June 2017. The target population was comprised of 
all students attending four public high schools located in both the urban and rural areas of Catalonia (Spain). Data from the current analyses were collected from the 1 st and 2 nd grade of obligatory secondary education (ESO). The sample consisted of 468 students, $49.4 \%$ being female. Participants were aged between 11 and 15 years old (mean age $=12.81$; standard deviation $(\mathrm{SD})=0.75)$.

Parents were given an information pack about the study, which included an informed consent form. A total of 326 parents did not provide consent and so their children did not take part in this study. Those students who returned a signed consent form from their parents were given a self-administered anonymous questionnaire, which was based on a validated Catalan survey: Risk Factors in Secondary School Students (FRESC). ${ }^{15}$ As FRESC did not include any questions about e-cigarette use in adolescents, the authors of this research added corresponding items to the questionnaire using the same question format.

Two trained researchers were present in the classroom to supervise questionnaire administration and answer any questions. The questionnaires were given to the students during a pre-arranged time (for 30-40 mins) which had been agreed with the schools. Every effort was made to ensure that the students had privacy while completing the questionnaire and the researchers collected the completed questionnaires as soon as each student had finished.

\section{Measures}

\section{Demographics}

Participants provided demographic data, including age, gender and school grade.

\section{Self-report of smoking tobacco or use e-cigarettes}

Adolescents indicated their lifetime consumption status for cigarettes and e-cigarettes by selecting one of the two options: "sometime in my life" or "never".

\section{Status regarding tobacco or e-cigarette smoking}

Participants were asked to select one of the eight possible responses about their current consumption status for smoking cigarettes and then for e-cigarette use. The eight response options were: "I smoke at least one cigarette (e-cigarette)/ day"; "I don't smoke every day, but have one cigarette (e-cigarette)/week"; "I don't smoke every week, but have one cigarette (e-cigarette)/month"; "I smoke less than onecigarette (e-cigarette)/month"; "I only smoke from time to time"; "I quit smoking cigarettes (e-cigarettes) after smoking once a week"; "I quit smoking cigarettes (e-cigarettes) after smoking less than once a week"; "I smoked cigarettes (e-cigarettes) once, but never will again". Adolescents who had never tried cigarettes or e-cigarettes or had given up smoking were labelled "non-smokers" and "non e- cigarette users", respectively. Those who currently used cigarettes or e-cigarettes at any frequency were labelled current "smokers" or "e-cigarette users", respectively.

\section{Age of onset for tobacco or e-cigarettes}

Adolescents indicated how old they were when they first smoked tobacco and first use e-cigarettes.

\section{Intention to smoke-cigarettes or use e-cigarettes in the future}

Participants were asked to indicate their future intention to smoke-cigarettes and their future intention to use e-cigarettes using the following eight response options: "I'm certain I will never smoke tobacco (use e-cigarettes) in the future"; "I don't think I will smoke tobacco (use e-cigarette) in the future"; "I think I will smoke tobacco (use e-cigarettes) sometime in the future"; "I think I will smoke tobacco (use e-cigarettes) in the next five years"; "I think I will smoke tobacco (use e-cigarettes) in the next year"; "I think I will smoke tobacco (use e-cigarettes) in the next six months"; "I think I will smoke tobacco (use ecigarettes) in the next month"; "I smoke tobacco (use ecigarettes) now". These two variables was both re-categorized into: I don't have the intention to consume in the future (which combined "I'm certain I will never smoke tobacco (use e-cigarettes) in the future"; "I don't think I will smoke tobacco (use e-cigarettes) in the future") and I have the intention of consume in the future (the other six options).

\section{The tobacco or e-cigarette smoking status of family members living at home}

Adolescents indicated the number of their family members at home that smoke tobacco or use e-cigarettes, respectively, with six possible responses: "No family member smokes tobacco or use e-cigarettes at home"; "one"; "two"; "three"; "four"; "five or more family members smoke tobacco or use e-cigarettes at home".

\section{Number of friends that smoke tobacco or use e-cigarettes}

Participants indicated the number of friends that smoke tobacco or use e-cigarettes, using one of these three options: "All or almost all"; "Some"; "None". 


\section{Perceived danger of tobacco or use e-cigarettes}

Participants indicated their perception of risk regarding smoking tobacco or using e-cigarettes, respectively, choosing from three options: "Very dangerous"; "Moderately dangerous"; "Not dangerous".

\section{Analysis}

Chi-square tests were used to analyze the relationships between two categorical variables, such as to compare the consumption status between participants who have a family member that smoked at home and those who did not. In order to choose the best predictors of the intention to consume tobacco and use e-cigarettes in the future (I have this intention; I do not have this intention), two stepwise binary logistic regression were undertaken. All analyses were performed using the statistical package for applied social sciences (SPSS), version 23.

\section{Ethics statement}

The Ethics and Biosecurity Research Committee at the University of Girona approved this study on May 4th, 2017 (reference number: CEBRU0002-2017). Written parental informed consent, student assent and permission from the authors of FRESC were obtained prior to data collection.

\section{Results}

In total $15 \%$ of the 468 participants $(n=70)$ had smoked at some time in their life, $5.8 \%(\mathrm{n}=27)$ were current tobacco smokers and $16.2 \%$ had the intention to smoke, or continue smoking, in the future. Regarding e-cigarettes, $7.5 \%$ $(n=35)$ of participants had used them at some time in their life, $2.5 \%(\mathrm{n}=12)$ were current users and $9.2 \%$ had the intention to use e-cigarettes (or continue consuming) in the future.

The age of onset for tobacco consumption ranged from 10 to 15 years old (mean 12.49 ; $\mathrm{SD}=1.03$ ), with the more frequent ages being $12(40 \%)$ and $13(34.5 \%)$. For e-cigarettes, the age range was between 10 and 15 (mean 12.71; $\mathrm{SD}=1.04)$, the most frequent age being 13 (48.4\%). Only 55 and 31 adolescents reported the age of onset for cigarettes and e-cigarettes, respectively.

Table 1 shows percentage of participants with family members smoking tobacco or using e-cigarettes at home, according their current consumption status and their intention to consume in the future. In all cases participants who smoke (tobacco or e-cigarettes) are more likely have family members who also smoke at home (tobacco or e-cigarettes), than participants who did not smoke (tobacco or e-cigarettes), but these differences were not significant. Participants who had the intention to consume (tobacco or e-cigarettes) in the future also more frequently had somebody who smoked tobacco ( $46.7 \%$ and $45.2 \%$, respectively) or used e-cigarettes $(5.4 \%$ and $11.9 \%$, respectively) at home, when compared with those who do not have this intention. These differences are significant except for the future intention to use tobacco when a family member used e-cigarettes at home.

Table 2 shows that more smokers $(87 \%)$ and e-cigarette users $(100 \%)$, than non-users $(53.3 \%$ and $54.4 \%$, respectively), had friends who smoked or used e-cigarettes. Similarly, more adolescents who had the intention to smoke or consume e-cigarettes in the future had friends that smoked or used e-cigarettes than those who did not have these intentions. In all cases, these differences were statistically significant.

There was a significant relationship between current consumption status and the intention to consume (or continue consuming) in the future. Current smokers were significantly more likely, than non-smokers, to report that they will smoke in the future (81.5\% vs $12.3 \%)$ and use e-cigarettes in the future (33.3\% vs $7.7 \%)$ (Table 3). Furthermore, current users of e-cigarettes were significantly more likely, than non-smokers, to report that they will smoke cigarettes $(72.7 \%$ vs $14.9 \%)$ and use e-cigarettes (63.6\% vs $7.9 \%)$ in the future (Table 3).

Table 4 shows participants' perceived risk of tobacco consumption, according to their current tobacco and e-cigarette consumption status and according to their intention to consume in the future. There was a clear pattern for users to report a lower level of risk than nonusers. These differences were all statistically significant, except for the comparison of current cigarette smokers vs non-smokers. However, it is important to note that the chi assumptions were not met for one of the comparisons (current cigarette smokers vs non-smokers).

Table 5 shows the results of a stepwise binary logistic regression to predict the intention to smoke tobacco in the future. The best predictors of the intention to consume in the future were: having tried tobacco, being a current consumer, having a family member smoking at home and having a low perceived risk of smoking. The probability of smoking in the future decreased by 5.26 times if they had never smoked, 16.7 times if they did not currently smoke, and 2.6 times if nobody smoked at home. In addition, the 
Table I Percentage of participants with family members smoking tobacco or using e-cigarette at home, according to their current consumption status and the intention to consume in future

\begin{tabular}{|c|c|c|}
\hline & n (\%) & $X^{2}$ ( $p$-value) \\
\hline \multicolumn{3}{|c|}{ Family member smokes tobacco at home } \\
\hline \multicolumn{3}{|c|}{ Tobacco cigarette user status } \\
\hline Smokers & $12(44.4)$ & $2.7(0.1)$ \\
\hline Non smokers & $129(29.5)$ & \\
\hline \multicolumn{3}{|c|}{ E-cigarette user status } \\
\hline Users & $8(72.7)$ & $-(0.28)^{\mathrm{a}}$ \\
\hline Non users & $12(50)$ & \\
\hline \multicolumn{3}{|c|}{ Future intention to use tobacco cigarette } \\
\hline I will smoke & $35(46.7)$ & $\mathrm{II} .3(0.00 \mathrm{I})^{* * *}$ \\
\hline I will not smoke & $106(27.2)$ & \\
\hline \multicolumn{3}{|c|}{ Future intention to use e-cigarettes } \\
\hline I will use & $19(45.2)$ & $5.1(0.02)^{*}$ \\
\hline I will not use & $120(28.5)$ & \\
\hline \multicolumn{3}{|c|}{ Family member uses e-cigarette at home } \\
\hline \multicolumn{3}{|c|}{ Tobacco cigarette user status } \\
\hline Smokers & $2(7.4)$ & $-(0.37)^{\mathrm{a}}$ \\
\hline Non smokers & $17(3.9)$ & \\
\hline \multicolumn{3}{|c|}{ E-cigarette user status } \\
\hline Users & $4(36.4)$ & $-(0.17)^{\mathrm{a}}$ \\
\hline Non users & $3(12.5)$ & \\
\hline \multicolumn{3}{|c|}{ Future intention to use tobacco cigarette } \\
\hline I will smoke & $4(5.4)$ & $-(0.52)^{\mathrm{a}}$ \\
\hline I will not smoke & $15(3.8)$ & \\
\hline \multicolumn{3}{|c|}{ Future intention to use e-cigarettes } \\
\hline I will use & $5(11.9)$ & $-(0.02)^{\mathrm{a}, *}$ \\
\hline I will not use & $13(3.1)$ & \\
\hline
\end{tabular}

Notes: a'Exact Fisher test. ${ }^{*} p \leq 0.05 ; * * 00.01 ; * * * 00.001$.

Table 2 Percentage of participants with friends who smoke tobacco or use e-cigarettes, according to their current consumption status and their intention to consume in the future

\begin{tabular}{|c|c|c|}
\hline & n (\%) & $X^{2}$ (p-value) \\
\hline \multicolumn{3}{|c|}{ My friends smoke tobacco cigarettes or use } \\
\hline \multicolumn{3}{|c|}{ e-cigarettes } \\
\hline \multicolumn{3}{|c|}{ Tobacco cigarette user status } \\
\hline Smokers & $20(87)$ & $9.8(0.002)^{* *}$ \\
\hline Non smokers & $176(53.3)$ & \\
\hline \multicolumn{3}{|c|}{ E-cigarette user status } \\
\hline Users & $12(100)$ & $9.8(0.002)^{* *}$ \\
\hline Non Users & $187(54.4)$ & \\
\hline \multicolumn{3}{|c|}{ Future intention to use tobacco cigarettes } \\
\hline I will smoke & $45(76.3)$ & $12.4(<0.001)^{* * *}$ \\
\hline I will not smoke & $|5|(5 \mid .4)$ & \\
\hline \multicolumn{3}{|c|}{ Future intention to use e-cigarettes } \\
\hline I will use & $33(86.8)$ & $9.8(0.002)^{* *}$ \\
\hline I will not use & $164(51.9)$ & \\
\hline
\end{tabular}

Note: $* p \leq 0.05 ; * * \leq 0.01 ; * * p \leq 0.001$. 
Table 3 Percentage of participants with the intention to smoke tobacco cigarettes or use e-cigarettes in the future, by current consumption status

\begin{tabular}{|c|c|c|c|c|c|c|}
\hline & $\begin{array}{l}\text { Smokers, } \\
\text { n (\%) }\end{array}$ & $\begin{array}{l}\text { Non smokers, } \\
\text { n (\%) }\end{array}$ & $X^{2}$ (p-value) & $\begin{array}{l}\text { E-cigarette users, } \\
\text { n (\%) }\end{array}$ & $\begin{array}{l}\text { Non e-cigarette } \\
\text { users, n (\%) }\end{array}$ & $X^{2}{ }_{1}(p$-value $)$ \\
\hline Will smoke & $22(81.5)$ & $54(12.3)$ & $\begin{array}{l}89.4 \\
(<0.00 \mathrm{I})^{* * *}\end{array}$ & $8(72.7)$ & $68(14.9)$ & $-(<0.00 \mathrm{I})^{\mathrm{a}, * * *}$ \\
\hline Will use e-cigarettes & $9(33.3)$ & $34(7.7)$ & $\begin{array}{l}19.88 \\
(<0.001)^{* * *}\end{array}$ & $7(63.6)$ & $36(7.9)$ & $-(<0.00 \mathrm{I})^{\mathrm{a}^{* * * *}}$ \\
\hline
\end{tabular}

Notes: ${ }^{a}$ Exact Fisher test. ${ }^{*} p \leq 0.05 ; * * 00.01 ; * * * \leq 0.001$

Table 4 Percentage of participants according their perceived risk of smoking tobacco and using e-cigarettes, their current consumption status and intention to consume in the future)

\begin{tabular}{|c|c|c|c|c|}
\hline & Not dangerous, n (\%) & Moderately dangerous, n (\%) & Very dangerous, $\mathbf{n}(\%)$ & $X^{2}{ }_{2}$ (p-value) \\
\hline Smoker & $2(7.4)$ & $18(66.7)$ & $7(25.9)$ & $1.2(0.54)^{\mathrm{a}}$ \\
\hline Non smoker & $15(3.5)$ & $286(66.2)$ & $|3|(30.3)$ & \\
\hline E-cigarettes user & $12(18.2)$ & $7(63.6)$ & $2(18.2)$ & $6.9(0.03)^{a, *}$ \\
\hline Non e-cigarettes user & $15(3.3)$ & $297(66.3)$ & $136(30.4)$ & \\
\hline Will smoke & $8(10.7)$ & $55(73.3)$ & $12(16)$ & $18.3(<0.00 \mathrm{I})^{\mathrm{a}, \text {,*** }}$ \\
\hline Won't smoke & $9(2.3)$ & $248(64.8)$ & $126(32.9)$ & \\
\hline Will use e-cigarettes & $5(11.9)$ & $28(66.7)$ & $9(21.4)$ & $9.5(0.009)^{\mathrm{a},{ }^{, * *}}$ \\
\hline Won't use e-cigarettes & $12(2.9)$ & $274(66)$ & $129(31.1)$ & \\
\hline
\end{tabular}

Notes: ${ }^{a}$ One or two cells have expected frequencies under five. ${ }^{*} p \leq 0.05 ;{ }^{* *} p \leq 0.01$; ${ }^{* * *} p \leq 0.001$.

probability of consuming increased 6.59 times if they believed smoking was not dangerous and 3.9 times, if they believed it to be moderately dangerous, compared with participants who perceived smoking to be very dangerous. The model explained $40 \%$ of variance (R square of Nagelkerke $=0.4)$ and correctly classified $88.4 \%$ of the participants.

The best predictors of the intention to consume e-cigarettes in the future are also shown in Table 5. The probability of consuming e-cigarettes in the future decreased by 3 times if they had never smoked, 6.7 times if they did not currently consume e-cigarettes and 4.5 times if their friends did not smoke and did not use e-cigarettes. This model explained $22.6 \%$ of the variance (R square of Nagelkerke $=0.226$ ) and correctly classified $90.7 \%$ of the participants.

\section{Discussion}

The lifetime prevalence of tobacco (15\% vs $7.5 \%)$ and ecigarette $(38.4 \%$ vs $17 \%)$ use in our sample were lower

Table 5 Predictors of the intention to smoke tobacco and use e-cigarettes in the future

\begin{tabular}{|l|l|l|l|}
\hline Predictors & Wald (p-value) & OR & 95\% CI \\
\hline Intention to smoke in the future & & & \\
Had smoked some time in their life & $15.2(<0.001)^{* * *}$ & 0.19 & $0.08-0.44$ \\
Currently smoke & $13.6(<0.001)^{* * *}$ & 0.06 & $0.02-0.27$ \\
Somebody smokes at home & $6.6(0.01)^{* *}$ & 0.39 & $0.19-0.80$ \\
Perceived danger & $6.9(0.03)^{*}$ & 6.59 & $1.50-28.97$ \\
Not dangerous & $6.2(0.01)^{* *}$ & 2.52 & $1.01-6.32$ \\
Moderately dangerous & $3.9(0.05)^{*}$ & & \\
\hline Intention to use e-cigarettes in the future & & 0.33 & \\
Had smoked some time in their life & $7.1(0.008)^{* *}$ & 0.15 & $0.14-0.74$ \\
Currently use e-cigarettes & $7.1(0.008)^{* *}$ & 0.22 & $0.07-0.61$ \\
My friends smoke or use e-cigarettes & $7.5(0.006)^{* *}$ & \\
\hline
\end{tabular}

Note: ${ }^{*} \leq 0.05 ;{ }^{*} \leq 0.01 ; * * * \leq 0.001$. 
than the figures reported in the Spanish national survey of high school students. ${ }^{1}$ The current consumption of conventional cigarettes was also lower $(31.4 \%$ vs $5.8 \%)$ than that found in the Spanish national survey. Furthermore, the most common ages to start smoking were 12 and 13 for cigarettes and e-cigarettes, while in the Spanish national survey they found this to be 14 years old. This discrepancy could be due to the fact that our study focused on a younger group of students (11-15 years old), than was the case in the Spanish national survey (14-18 years old). In support of this explanation, research has found that the use of cigarettes or e-cigarettes increases with age ${ }^{2}$ and thus we would expect a lower prevalence would be found in a younger sample.

Teenagers are particularly vulnerable to addictive effects of nicotine and other substances, due in part to the fact that they are still going through critical periods of growth and development. Furthermore, the World Health Organization (WHO) reports that the adolescents who try cigarettes at an early age are among the heaviest users in adulthood. ${ }^{14}$ More than $93 \%$ of those who start smoking before 13 years old have a high risk of tobacco addiction. WHO also reports that there is a paucity of research investigating trends in the consumption of tobacco products by adolescents aged 13-15 years or younger. ${ }^{14}$ The present study highlights the fact that a substantial number of teenagers had tried smoking cigarettes or e-cigarettes at a very young age. Therefore, preventive measures which are implemented at an early age to delay the age of experimentation or to stop smoking initiation should produce substantial benefits.

The present study found that $16 \%$ of participants had the intention to smoke or to continue smoking tobacco, while nearly one in ten adolescents had the intention to use e-cigarettes in the future. In agreement with previous research, the intention to smoke or use e-cigarette among adolescents is influenced by personal and external factors, such as psychological, social and environmental. ${ }^{16}$ The current findings also suggest that prevention interventions need to also consider the addictive power of these tobacco products, even when the process is at an early stage.

Having family members who smoked at home significantly increased the risk of experimentation with e-cigarettes and tobacco. ${ }^{1}$ The present study also found significantly higher percentages of cigarette smoking and e-cigarette consumption among adolescents who had smokers or e-cigarette users at home. The intention to consume in the future was higher in both cases, but only significant when somebody at home used e-cigarettes. In line with previous research, peer group influence emerged as a key predictor of current smoking behaviour among adolescents and intention to smoke in the future. ${ }^{17-19}$ Almost nine out of ten tobacco smokers, and all of the e-cigarette smokers in our study, had friends that smoked or used e-cigarettes. The relationship between intention to smoke cigarettes or e-cigarettes in the future and having friends that currently smoked tobacco or e-cigarettes was also statistically significant. As Bandura ${ }^{20}$ suggested, people learn from those who are close to them. The behaviour of parents, friends and siblings could have an indirect effect on individuals due to the dynamic and reciprocal relationship between observational learning, personal factors, expectancies, reinforcement, self-efficacy and reciprocal determinism.

Our findings confirm that current smokers and e-cigarette users perceive tobacco and e-cigarette consumption to be less dangerous than those who are not currently consumers (of tobacco or e-cigarettes). Moreover participants that reported no intention to smoke cigarettes or to use e-cigarettes either in the future perceived each to be more risky than those who reported the intention to smoke cigarettes or use e-cigarettes in the future. This finding is in agreement with previous research, which has found a lower perception of risk among adolescents that consume tobacco or e-cigarettes and higher perceived risk among those who do not use these substances. ${ }^{1,21}$

The results of this study suggest that having previously smoked is one of the best predictors of future intention to smoke tobacco or use e-cigarettes among adolescents. This finding is particularly concerning, since various well-supported theoretical models indicate that intention is a good predictor of future behaviour. ${ }^{22,23}$ Also in accordance with previous research, ${ }^{24}$ we found that the most influential variable, regarding teenager's intention to smoke cigarettes or e-cigarettes in the future, was the current use of cigarettes or e-cigarettes. Furthermore, the findings of this research support the hypothesis that the perceived smoking environment, such as parents or friends smoking behaviour, affects the motivation of teenagers to smoke or use e-cigarettes in the future. The lack of perceived danger has also been found to be another strong predictor of intention to smoke among adolescents. ${ }^{25}$

In accordance with other studies, ${ }^{26,27}$ our findings highlight the fact that smoking prevention programs must also consider the network surrounding teenagers, especially close family and peers and that prevention programs must be implemented at the start of the teenage years. 


\section{Limitations}

The present study has several limitations. Firstly, the present study used a cross-sectional design, which means that it is not possible to infer causality. Secondly, the data were collected from adolescents living in small cities, which may not be representative of the general population of adolescents. Finally, although the questionnaire was anonymous, the results may have been affected by social desirability bias.

\section{Conclusion}

Family-based interventions, combined with school, media and community preventive actions can provide useful tools for families, children and adolescents to resist starting, or continuing to use, tobacco or e-cigarettes. Guidance for parents and families must emphasize the positive effects of quitting smoking, especially during pregnancy and the child's first year. It is also important that preventive interventions focus on the knowledge, beliefs and attitudes of parents, caregivers, children and adolescents regarding smoking and its consequences. Parents must be informed that their children will observe their behaviour, which they may then copy. It is also important to strengthen teenager's social competencies and skills needed to avoid the initiation of smoking and e-cigarette use among children and teenagers. Delaying the onset of tobacco or e-cigarette consumption in adolescents is crucial in preventing later addiction.

In order to more fully understand the characteristics that influence the intention to consume, initiation and maintenance of smoking cigarettes or e-cigarettes among teenagers, more longitudinal studies must be carried out throughout adolescence. Examining the relationship between cigarette use and e-cigarette use along with their short term, medium term and long term effects may also help to prevent the early onset of smoking.

\section{Disclosure}

The authors report no conflicts of interest in this work.

\section{References}

1. Ministerio de Sanidad, Servicios Sociales e Igualdad. ESTUDES 2016. Encuesta Sobre Uso De Drogas En Enseñanzas Secundarias En España. Madrid, España: Ministerio de Sanidad Servicios Sociales e Igualdad; 2018.

2. Chacón R, Castro M, Caracuel R, et al. Profiles of alcohol and tobacco use among adolescents from Andalusia in the first cycle of secondary education. Health Addict. 2016;16(2):93-104.

3. Liquete L, Pérez E, Marugán JM, et al. Riesgo percibido sobre el consumo ocasional de tabaco tradicional y electrónico en adolescentes. Rev Pediatr Aten Primaria. 2017;19(74):127-136.
4. Díez JM. La importancia de la educación para la prevención del inicio del consumo de tabaco entre los estudiantes adolescentes. Rev Patol Respir. 2014;17(03):77-78.

5. Pénzes M, Floey KL, Nadasan V, Paulik E, Ábrám Z, Urbán R. Bidirectional associations of e-cigarette, conventional cigarette and waterpipe experimentation among adolescents: a cross-lagged model. Addict Behav. 2018;80:59-64. doi:10.1016/j.addbeh.2018.01.010

6. Lidón-Moyano C, Martínez-Sánchez JM, Fu M, et al. Prevalencia y perfil de uso del cigarrillo electrónico en España (2014). Gac Sanit. 2016;30(6):432-437. doi:10.1016/j.gaceta.2016.03.010

7. Tsai J, Walton K, Coleman BN, et al. Reasons for electronic cigarette use among middle and high school students - National Youth Tobacco Survey, United States, 2016. Morb Mortal Wkly Rep. 2018;67(6):196-200. doi:10.15585/mmwr.mm6731e2

8. Owotomo O, Maslowsky J, Loukas A. Perceptions of the harm and addictiveness of conventional cigarette smoking among adolescent ecigarette users. J Adolesc Health. 2018;62(1):87-93. doi:10.1016/j. jadohealth.2017.08.007

9. Evans-Polce RJ, Patrick ME, Lanza ST, Miech RA, O’Malley PM, Johnston LLD. Reasons for vaping among U.S. 12th graders. $J$ Adolesc Health. 2018;62(4):457-462. doi:10.1016/j.jadohealth.2017.10.009

10. Hilton S, Weishaar H, Sweeting H, Trevisan F, Katikieddi SV. Ecigarettes, a safer alternative for teenagers? A UK focus group study of teenagers' views. BMJ Open. 2016;6:e013271. doi:10.1136/bmjopen-2016-013271

11. Pepper JK, Farrelly MC, Watson KA. Adolescent's understanding and use of nicotine in e-cigarette. Addict Behav. 2018;82:109-113. doi:10.1016/j.addbeh.2018.02.015

12. Miech RA, Johnston LLD, O'Malley PM, Bachman JG, Schulenberg JE. Monitoring the Future National Survey Results on Drug Use, 1975-2015: Volume I, Secondary School Students. Ann Arbor: Institute for Social Research. University of Michigan; 2016.

13. National Center for Chronic Disease Prevention and Health Promotion (US).Office on Smoking and Health. Preventing Tobacco Use among Youth and Young Adults. A Report of the Surgeon General. Atlanta (GA): Centers for Disease Control and Prevention (US); 2012.

14. World Health Organization (WHO). Global Report on Trends in Prevalence of Tobacco Smoking 2000-2025. 2nd ed. Geneva: World Health Organization; 2018.

15. Agència de Salut Pública de Barcelona. Informe FRESC 2012. 25 anys d'enquestes a adolescents escolaritzats a Barcelona. Barcelona: Agència de Salut Pública de Barcelona; 2012. Available from: https:// www.aspb.cat/wp-content/uploads/2016/05/Informe_FRESC_2012. pdf. Accessed October 3, 2018.

16. Vitoria PD, Salgueiro MF, Silva SA, De Vries H. Social influence, intention to smoke and adolescente smoking behaviour longitudinal relations. Br J Health Psychol. 2011;16(4):779-798. doi:10.1111/ bjhp.2011.16.issue-4

17. Ferreira M, Torgal M. Tobacco and alcohol consumption among adolescents. Rev La Am Enferm. 2010;18(2):255-261. doi:10.1590/ S0104-11692010000200017

18. Vasilopoulos A, Gourgoulianis K, Hatzoglou CH, Roupa Z. Social influence and smoking habit in adolescent. Health Sci J. 2015;9(2):1-4.

19. Liu J, Zhao S, Chen X, Falk EB, Albarracín D. The influence of peer behaviour as a function of social and cultural closeness: a metaanalysis of normative influence on adolescent smoking initiation and continuation. Psychol Bull. 2017;143(10):1082-1115. doi:10. 1037/bul0000113

20. Bandura A. Pensamiento Y Acción. Barcelona: Martínez Roca; 1987.

21. Roditis M, Delucchi K, Cash D, Halpen-Felsher B. Adolescent's perceptions of health risks, social benefits differ across tobacco products. J Adolesc Health. 2016;58(5):558-566. doi:10.1016/j. jadohealth.2016.01.012

22. Ajzen I. From intention to action: a theory of planned behaviour. In: Kull J, Beckmann J, editors. Action Control from Cognition to Behaviour. Berlin: Springer -Verlog; 1985:11-38. 
23. Ajzen I. Attitudes, Personality, and Behaviour. Bristol: Open University Press; 1988.

24. Calleja N, Aguilar J. Por qué fuman las adolescentes: un modelo estructural de la intención de fumar. Adicciones. 2008;20(4):387-394.

25. Zhu C, Cai Y, Ma J, et al. Predictors of intention to smoke among junior high school students in Shangai, China: an empirical test of the information-motivation-behavioural skills (IMB) model. PLoS One. 2013;8:e80482. doi:10.1371/journal.pone.0080482
26. Harvey J, Chadi N. Preventing smoking in children and adolescents: recommendations for practice and policy. Paediatr Child Health. 2016;21(4):209-214. doi:10.1093/pch/21.4.209

27. Eldalo A. Prevalence and perception of smoking habits among the Palestinian population in the Gaza strip. J Multidiscip Healthc. 2016;9:297-301. doi:10.2147/JMDH.S107346

\section{Publish your work in this journal}

The Journal of Multidisciplinary Healthcare is an international, peerreviewed open-access journal that aims to represent and publish research in healthcare areas delivered by practitioners of different disciplines. This includes studies and reviews conducted by multidisciplinary teams as well as research which evaluates the results or conduct of such teams or healthcare processes in general. The journal covers a very wide range of areas and welcomes submissions from practitioners at all levels, from all over the world. The manuscript management system is completely online and includes a very quick and fair peer-review system. Visit http://www.dovepress.com/testimonials. php to read real quotes from published authors. 